\title{
Impact of Angiotensin-Converting Enzyme Inhibitors and Angiotensin II Receptor Blockers on the Long-Term Outcome after Pulmonary Vein Isolation for Paroxysmal Atrial Fibrillation
}

\author{
Hanno U. Klemm ${ }^{a}$ Thomas Heitzer ${ }^{a} \quad$ Ute Ruprecht $^{a} \quad$ Thomas Meinertz $^{b}$ \\ Rodolfo Ventura ${ }^{c}$ \\ ${ }^{a}$ Department of Cardiology, Heart Center Dortmund, Dortmund, ${ }^{b}$ Department of Cardiology, University \\ Heart Center Hamburg, Hamburg, and 'Electrophysiology Bremen, Bremen, Germany
}

\section{For editorial comment see p. 11}

\section{Key Words}

Atrial fibrillation - Angiotensin-converting enzyme inhibitors · Angiotensin II receptor blockers · Pulmonary vein isolation $\cdot$ Catheter ablation

\begin{abstract}
Objectives: The effect of angiotensin-converting enzyme inhibitors (ACE-I) and angiotensin II receptor blockers (ARBs) on the long-term outcome after pulmonary vein isolation (PVI) for paroxysmal atrial fibrillation (PAF) is unknown. Methods: This matched-pair study included 102 patients with PAF treated with ACE-I or ARBs (group 1) and 102 control subjects (group 2) after standardized PVI. Tele-ECG recorders were used to detect the end point of the first PAF recurrence after a 3-month blanking period. Results: Median follow-up was 2.1 years (range 0.3-6.3). In group 1, 51 (50\%) patients suffered recurrences, with a mean time to recurrence of 3.2 years (95\% Cl 2.6-3.8). In group 2, 67 (65.7\%) patients presented PAF after a mean period of 2.2 years $(95 \% \mathrm{Cl} 1.7-2.8$; $p=0.009)$. A second ablation was performed in 31 (50\%) patients from the treatment group and in 48 (66.7\%) patients from the control group $(p=0.02)$. Multivariate Cox analysis showed treatment with ACE-I and ARBs to be the only sig-
\end{abstract}

nificant predictor of a reduced recurrence rate (HR 0.49, 95\% $\mathrm{Cl}$ 0.32-0.75). Conclusion: ACE-I and ARBs were effective for the preservation of sinus rhythm after PAF ablation, and they reduced the reablation rate.

\section{Introduction}

The fundamental principles underlying paroxysmal atrial fibrillation (AF) have been elucidated in the last decade with the development of effective ablation strategies [1-3]. The importance of focal activity to initiate or even sustain AF has led to the approach of pulmonary vein isolation to cure the paroxysmal form of $\operatorname{AF}[4,5]$. The left atrial myocardium as the substrate of self-perpetuating AF, however, is subject to chronic changes as a result of stretch and inflammation. Evidence that supports a crucial role of the renin-angiotensin-aldosterone system (RAAS) has been obtained from experimental and clinical studies [6-10].

While the beneficial effects of angiotensin-converting enzyme inhibitors (ACE-Is) and angiotensin II type 1 receptor blockers (ARBs) have been established after car-

\section{KARGER}

Fax +4161306 1234 E-Mail karger@karger.ch www.karger.com
(C) 2010 S. Karger AG, Basel

0008-6312/10/1171-0014\$26.00/0

Accessible online at:

www.karger.com/crd
Hanno U. Klemm, MD, MSc

Department of Cardiology, Heart Center Dortmund

Beurhausstrasse 40, DE-44137 Dortmund (Germany)

Tel. +49 231953 20600, Fax +4923195321500

E-Mail hanno.klemm@klinikumdo.de 
dioversion of persistent AF $[11,12]$, their role after the ablation of paroxysmal AF remains to be defined.

Conduction recovery of pulmonary veins has been postulated to be the major determinant of AF recurrence during short-term follow-up [13, 14]. After a second or even a third ablation procedure, conduction recovery is reduced and its role in the initiation and maintenance of AF seems less important. In the present study, we sought to identify the impact of ACE-Is and ARBs on the outcome after a standardized ablation procedure for paroxysmal AF. We postulated that beneficial effects would be observable in the long run rather than in the short run.

\section{Methods}

\section{Patients}

From a single-center database of 626 patients, 204 patients ablated between 2001 and 2006 were included in the analysis. All patients were treated for the first time for highly symptomatic paroxysmal AF by segmental ostial ablation of all pulmonary veins. Patients with prior episodes of persistent $\mathrm{AF}$ or AF ablation were excluded. Treatment with ACE-Is or ARBs was established at the time of ablation in 102 patients (group 1). Incorporating a matched-pair design, for each patient of group 1 a corresponding patient was selected from the database (group 2) that matched according to the following parameters: gender, age ( \pm 5 years), and date of ablation procedure ( \pm 6 months).

All patients were refractory to conventional antiarrhythmic therapy with a median of 2 drugs (range 1-4) remaining ineffective. Patients were screened prior to the ablation procedure at our outpatient department. Holter-ECG recordings revealed frequent symptomatic episodes, with more than 1 episode at least $5 \mathrm{~min}$ in duration within $24 \mathrm{~h}$ for each patient. The baseline characteristics of the patient cohort are given in table 1 .

\section{Ablation Procedure}

Two long sheaths were advanced to the left atrium via a double transseptal puncture or a patent foramen ovale. Mapping was performed using a decapolar circumferential catheter (Lasso; Biosense Webster, Diamond Bar, Calif., USA) during sinus rhythm (SR). A radiofrequency current was applied via an open irrigated 3.5-mm tip electrode catheter (ThermoCool; Biosense Webster) in a combined power- and temperature-guided mode [15]. Segmental pulmonary vein isolation was performed at ostial sites with a power of $25-30 \mathrm{~W}$ at a saline solution flow of $30 \mathrm{ml} / \mathrm{min}$ and an upper temperature limit of $50^{\circ} \mathrm{C}$. After isolation of the veins, an irrigated tip ablation of the right atrial isthmus, described elsewhere [16], was performed. The complete entrance blockage of all pulmonary veins and bidirectional isthmus blockage was the end point of ablation. Blockage was verified by the elimination of all pulmonary vein potentials and by pacing maneuvers at a minimum of $30 \mathrm{~min}$ after ablation. Patients were administered oral anticoagulation (international normalized ratio 2.0-3.0) for 3 months followed by a treatment regimen in concor-
Table 1. Preablation baseline characteristics

\begin{tabular}{|c|c|c|c|}
\hline & $\begin{array}{l}\text { Group } 1 \\
\text { (ACE-I/ARB) }\end{array}$ & $\begin{array}{l}\text { Group 2 } \\
\text { (control) }\end{array}$ & $\mathrm{p}$ \\
\hline Patients (males), $\mathrm{n}^{1}$ & $102(66)$ & $102(69)$ & 0.66 \\
\hline Approximate date & Jan. 2005 & Oct. 2004 & \\
\hline $\begin{array}{l}\text { of ablatio } \\
\text { Age, years }{ }^{1}\end{array}$ & $\begin{array}{l} \pm 15 \mathrm{~m} \\
63 \pm 7\end{array}$ & $\begin{array}{l} \pm 17 \mathrm{~m} \\
62 \pm 8\end{array}$ & $\begin{array}{l}0.16 \\
0.15\end{array}$ \\
\hline Coronary artery disease, $\mathrm{n}$ & $12(11.7 \%)$ & $5(4.9 \%)$ & 0.08 \\
\hline Mitral regurgitation, $\mathrm{n}^{2}$ & $1(1 \%)$ & 0 & 0.32 \\
\hline Arterial hypertension, $\mathrm{n}$ & $88(86.3 \%)$ & $41(40.2 \%)$ & $<0.01$ \\
\hline Diabetes, $\mathrm{n}$ & $8(7.8 \%)$ & $7(6.9 \%)$ & 0.79 \\
\hline LA diameter, $\mathrm{mm}$ & $44 \pm 6$ & $45 \pm 7$ & 0.82 \\
\hline Impaired LV function, $\mathrm{n}$ & $3(2.9 \%)$ & $2(2 \%)$ & 0.65 \\
\hline Amiodarone, $\mathrm{n}$ & $28(27.4 \%)$ & $21(20.6 \%)$ & 0.25 \\
\hline Sotalol, $\mathrm{n}$ & $8(7.8 \%)$ & $5(4.9 \%)$ & 0.39 \\
\hline Class IC AA, $\mathrm{n}$ & $31(30.4 \%)$ & $27(26.5 \%)$ & 0.53 \\
\hline Beta-blockers, n & $62(60.7 \%)$ & $42(41.2 \%)$ & $<0.01$ \\
\hline Statins, $\mathrm{n}$ & $19(18.6 \%)$ & $11(10.8 \%)$ & 0.11 \\
\hline
\end{tabular}

$\mathrm{LV}=$ Left ventricular; $\mathrm{LA}=$ left atrial; $\mathrm{AA}=$ antiarrhythmic drugs. ${ }^{1}$ Variable used for subject matching. ${ }^{2}$ Moderate.

dance with the AF treatment guidelines at that time [17]. Antiarrhythmic therapy was continued for 3 months postablation.

In case of a second ablation procedure the same approach was used. No ablation was performed on veins that showed persistent blockage after the first ablation.

Follow-Up

Patients were discharged in SR after 2 days of monitoring. In case of in-hospital AF recurrence, electric cardioversion was performed. Patients were supplied with a credit card-sized ECG recorder (RhythmCard; Instromedix, San Diego, Calif., USA) capable of storing up to 3 single-lead ECGs with a fixed length of $1 \mathrm{~min}$. Patients were prompted to record at least 1 ECG per day irrespective of symptoms and upon any occurrence of symptoms [18]. Intensified follow-up via tele-ECG was continued for 6 months postablation and stored in a database. The tele-ECGs were analyzed by 2 independent cardiologists and diagnosed as SR or $\mathrm{AF}$ at least $30 \mathrm{~s}$ in duration. Due to the limited capability to differentiate atrial rhythms, suspected postablation arrhythmias, i.e. focal atrial tachycardia or left atrial flutter, with fast and irregular QRS complexes were treated as AF recurrences.

\section{Study End Points}

The primary end point of this study was the first documented recurrence of AF. A 3-month blanking period was used to handle early recurrences related to the acute phase of ablation. Off-drug recurrence rates were also evaluated at 6 and 12 months postablation.

Secondary end points were the need for reablation, recurrence after reablation, and the absence of AF at the end of the follow-up evaluation period. 
Table 2. Treatment regimen of group 1 with RAAS-modulating drugs

\begin{tabular}{lll}
\hline & $\mathrm{n}$ & Daily dose, mg \\
\hline ACE-I & $62(60.8 \%)$ & \\
Ramipril & $31(50 \%)$ & $5.6(2.5-10)$ \\
Enalapril & $13(21 \%)$ & $8.1(5-10)$ \\
Lisinopril & $8(12.9 \%)$ & $20(10-40)$ \\
Other & $10(16.1 \%)$ & \\
\hline ARBs & $40(39.2 \%)$ & \\
Candesartan & $13(32.5 \%)$ & $16(8-32)$ \\
Irbesartan & $10(25 \%)$ & $225(150-300)$ \\
Valsartan & $10(25 \%)$ & $116(80-160)$ \\
Other & $7(17.5 \%)$ & \\
\hline
\end{tabular}

The daily dose values are presented as means (ranges).

Ethics

All procedures were performed in accordance with the ethical standards of the local ethics committee on human experimentation and the Helsinki Declaration. All patients provided their written informed consent.

\section{Statistical Analysis}

The study was performed using a matched-pair design. Patients were not randomized for the treatment regimen. ACE-I or $\mathrm{ARB}$ therapy, however, remained unchanged during follow-up. Continuous variables are presented as means \pm standard deviation. Student's t test was used to evaluate differences in continuous variables. A $\chi^{2}$ test was applied for the cross tabulation of raw event rates. The mean time to AF recurrence and the $95 \%$ confidence intervals (CI) were calculated using Kaplan-Meier survival analysis. The Cox proportional hazards model was applied to identify and adjust for potential confounders. An adjusted logrank test was used to compare the time-to-event recurrence curves. Raw event rates are given in flow chart diagrams. All tests were 2-tailed, and $\mathrm{p}<0.05$ was considered statistically significant. Analyses were performed using SPSS version 14 (SPSS Inc., Chicago, Ill., USA).

\section{Results}

A control patient was assigned to each patient in the treatment group. The characteristics of the matched variables for both groups are presented in table 1. During the first pulmonary vein isolation, 358 (87.7\%) and 361 (88.4\%) of the 408 target veins were successfully ablated in the ACE-I or ARB group (group 1) and in the control group (group 2), respectively. In 7 patients, a third right pulmonary vein was detected but not ablated due to small diameters. Radiofrequency current was applied for 48.3 $\pm 22.3 \mathrm{~min}$ in group 1 and for $46.5 \pm 18.2 \mathrm{~min}$ in group 2. The right atrial isthmus was blocked bidirectionally in 189 (92.6\%) patients. No differences between the 2 groups with regard to fluoroscopy duration $(55.2 \pm 19.9$ vs. 56.4 $\pm 21.8 \mathrm{~min})$ or procedure time $(4.8 \pm 1.7$ vs. $4.9 \pm$ $1.6 \mathrm{~h})$ were detected.

\section{Treatment with ACE-Is and ARBs}

In group 1, sixty-two (60.8\%) patients received ACE-Is. The remaining 40 (39.2\%) were treated with ARBs. Therapy was initiated in all patients at least 2 months prior to ablation and continued unchanged during follow-up. The minimum and maximum doses recommended by the manufacturer were taken by 35 (34.3\%) and 23 (22.5\%) patients, respectively. Detailed data on the drugs effective in the study population are given in table 2 . Indications for therapy with ACE-Is or ARBs were arterial hypertension $(n=88)$, coronary artery disease $(n=12)$, and left ventricular dysfunction $(n=3)$. Patients with coronary artery disease were concomitantly treated with statins. Beta-blockers as primary antiarrhythmic agents were discontinued in 9 of the 62 patients on the drugs postablation.

\section{Drug Treatment of the Control Group}

Patients in group 2 received beta-blockers in 42 cases for the treatment of arterial hypertension. As in group 2, therapy had been initiated at least 2 months prior to ablation and continued unchanged throughout the follow-up period in each case. Five patients with coronary artery disease were on statin therapy.

\section{Outcome after Primary Ablation}

After a median follow-up interval of 2.1 years (range $0.3-6.3), 51$ (50\%) of the 102 patients in group 2 (treatment group) remained AF free (fig. 1). No recurrences were detected in $32(34.3 \%)$ of the 102 patients in group 2 $(\mathrm{p}=0.023)$. The mean time to recurrence was 3.2 years (95\% CI 2.6-3.8) and 2.2 years (95\% CI 1.7-2.8) for groups 1 and 2, respectively. Kaplan-Meier plots for the primary end point of first recurrence of AF are presented in figure 2. Multivariate Cox analysis (fig. 3) showed treatment with ACE-Is or ARBs to be the only significant predictor of the absence of AF (HR 0.49, 95\% CI 0.32-0.75, p = 0.001). For arterial hypertension, however, more recurrences were identified in the AF patient cohort (HR 1.72, $95 \%$ CI $1.12-2.66, \mathrm{p}=0.014)$. In a subanalysis 6 months after ablation, $64(62.7 \%)$ patients from the treatment group and 44 (42.2\%) patients from the control group re- 
Fig. 1. Flow chart of the study design. Patients with paroxysmal atrial fibrillation and concurrent treatment with ACE-Is or ARBs were subsumed into group 1 . For each patient in group 1 a control patient (group 2) was selected that matched in gender, age, and ablation date. All patients underwent segmental ostial isolation of the pulmonary veins. Patients with recurrences were offered a repeat procedure. ${ }^{1}$ Absence of AF after a 3-month blanking period. Fig. 2. The Kaplan-Meier plot shows the cumulative proportion of patients without AF recurrence after the first ablation following a 3-month blanking period. The log-rank test was significant $(\mathrm{p}=0.009)$.

Fig. 3. $\mathrm{HR}, 95 \% \mathrm{CI}$, and $\mathrm{p}$ values for the Cox proportional hazards model. Treatment with ACE-Is and ARBs was the only significant predictor of the absence of AF. Patients with arterial hypertension, however, presented significantly more recurrences.

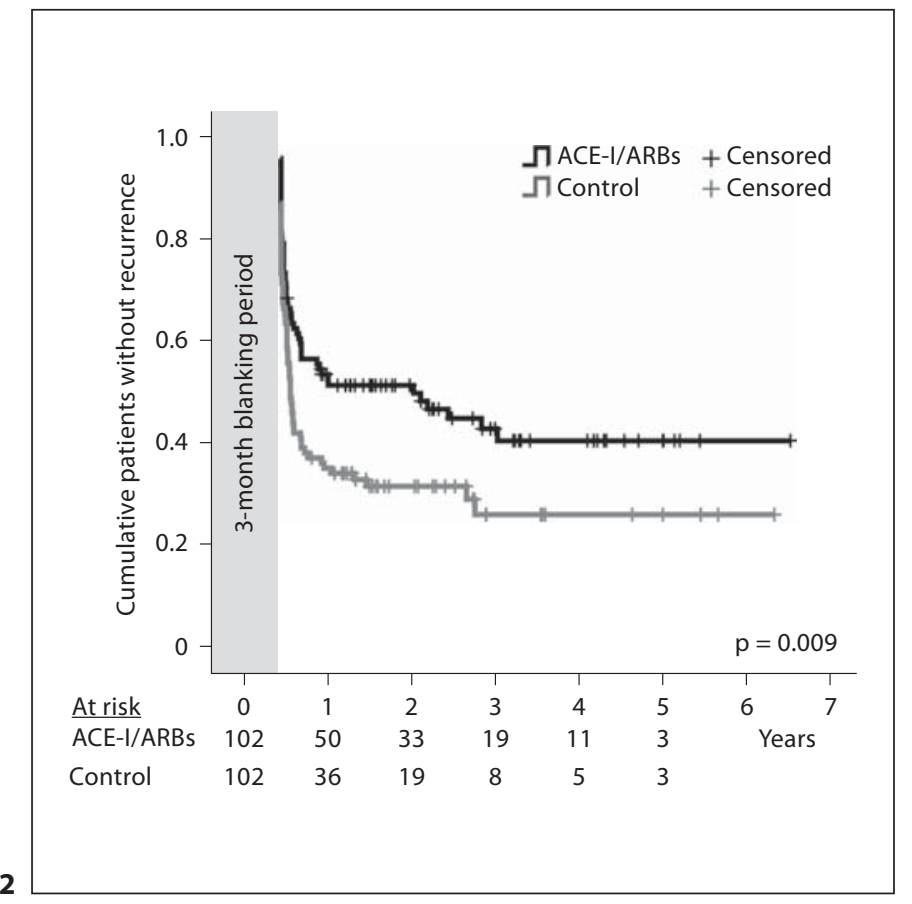

ACE-I and ARBs after Pulmonary Vein Isolation
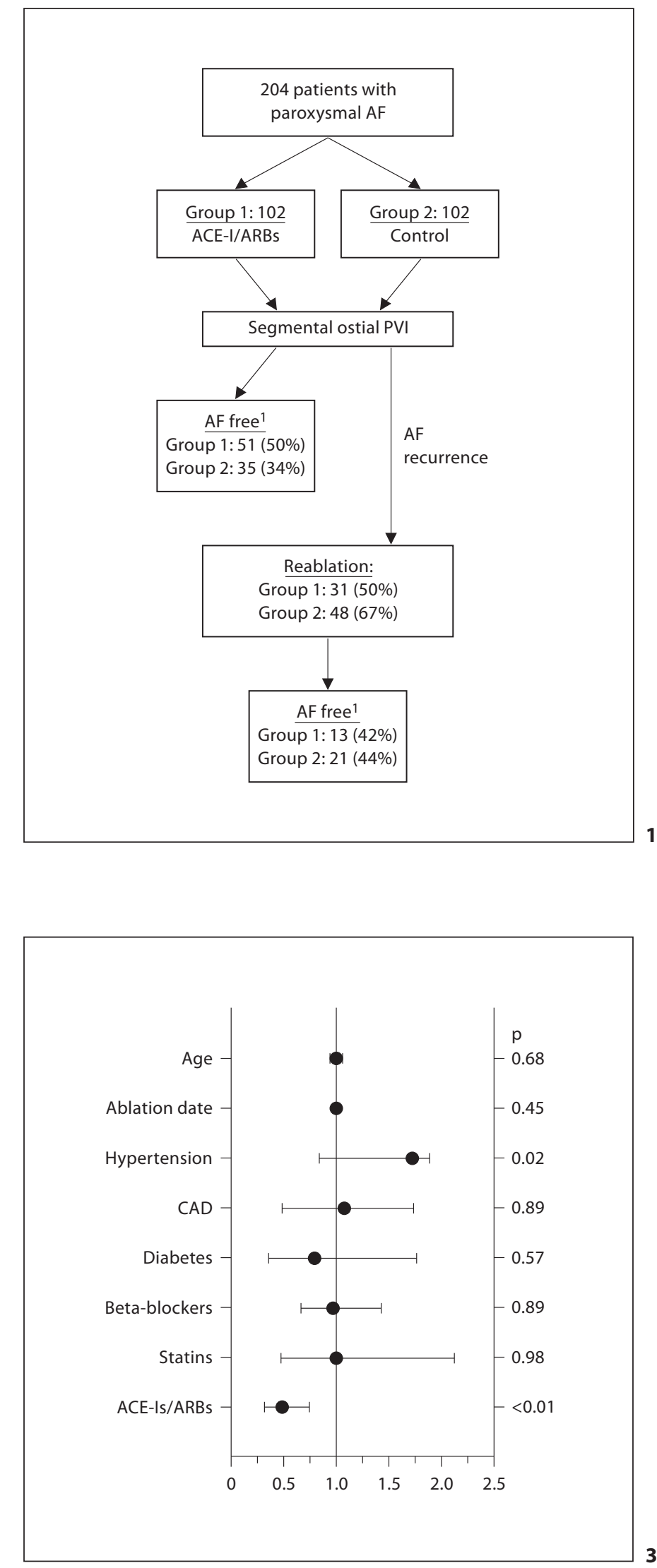

Cardiology 2010;117:14-20 
mained in SR ( $\mathrm{p}=0.005)$. After 12 months, 56 patients (54.9\%) from group 1 and 39 patients (38.2\%) from group 2 had had no AF recurrence ( $\mathrm{p}=0.017)$.

A subgroup analysis revealed a nonsignificant difference of $33(53.2 \%)$ recurrences for patients on ACE-I treatment and 18 (45\%) recurrences during ARB therapy $(\mathrm{p}=0.54)$.

\section{Outcome after Reablation}

Reablation was performed in 31 (50\%) patients with AF recurrence in group 1, whereas the other half preferred conservative treatment. In the control group (group 2), 48 (67\%) patients with recurrences were ablated and $24(33 \%)$ opted for drug treatment $(\mathrm{p}=0.05)$. After a median period of 1 year (range 0.1-5.9) following reablation, 13 (42\%) patients from the treatment group (group 1) remained in SR (fig. 1). In the control group, 21 (44\%) patients were recurrence free $(\mathrm{p}=0.87)$.

At the end of the follow-up period, 64 (62.7\%) patients in group 1 and 56 (54.9\%) patients in group 2 were in SR after a mean of 1.3 and 1.5 ablation procedures, respectively.

\section{Discussion}

The present study supports the importance of RAAS in the pathophysiology of AF. Several experimental and clinical studies have addressed the influence of each of these drugs in various settings of new-onset [19-21] or recurrence of AF $[12,22]$. Trials emphasizing the influences on self-sustained persistent AF have correlated drug treatment with fewer recurrences after electric cardioversion $[11,12]$. In agreement with these studies, our data show divergence of the Kaplan-Meier plots at the first 12 months of follow-up. At that time, 54.9\% of patients in the treatment group remained $\mathrm{AF}$ free compared to $38.2 \%$ of the patients in the control group. Assuming that the rate of pulmonary vein conduction recovery is equal in both groups, ACE-Is and ARBs may prevent focal arrhythmias or reverse the development of a fibrillating substrate that is less dependent on focal pulmonary vein activity.

This effect becomes evident after the acute-phase postablation. In addition, the significantly greater number of patients with recurrences in the first weeks postablation supports the medium-term beneficial effects.

In a recent publication by Richter et al. [23], no effect on the outcome after AF ablation could be demonstrated. Although a comparable group size was chosen, the sub- jects presented paroxysmal and persistent forms of $\mathrm{AF}$ and were ablated using segmental ostial and purely anatomical approaches. In particular, isolation of the pulmonary veins was the end point for a minority (35\%) of the patients. A similar study by Al Chekakie et al. [24] demonstrated a favorable outcome with ARBs, though it was not statistically significant due to a limited number of patients. As in the Richter et al. [23] study no effect could be attributed to the intake of statins. The deviant results as compared to our investigation may stem from the smaller number of patients presenting both paroxysmal and persistent AF. A clinically relevant aspect not addressed by the 2 studies is the reablation rate which could be reduced from 67 to $50 \%$ relating to a long-term efficacy of RAAS blockade despite limited AF recurrences.

From the study design it is not possible to conclude that the beneficial action of ACE-Is and ARBs is related to atrial remodeling $[25,26]$. Atrial fibrosis is promoted by angiotensin II as a result of the upregulation of the RAAS [27]. Further modes of action include hemodynamic changes with reduced left atrial pressure and wall stress [28].

The clinical relevance of early recurrences in combination with a late cure remains controversial [18, 29-31] and is possibly linked to the acute upregulation of inflammatory processes after ablation indicated by increased C-reactive protein and fibrinogen levels [32]. Both ACE-Is and ARBs are modulators of the inflammatory pathway $[33,34]$ and may therefore also be effective during the early phase after AF ablation.

Since the treatment regimen was not randomized, dosing of ACE-Is and ARBs varied individually within the recommended ranges. A maximum dosage was taken by a minority (23\%) of the group 1 patients. Although speculations remain regarding whether the effects could be intensified by a higher drug intake, prior studies on AF prevention used intermediate doses of the studied agents $[9,11,12]$.

The subsumption of patients on ACE-I and ARB treatment into group 1 may not seem justified as the mode of action of the 2 agents is not identical. Indeed, human atrial tissue locally expresses ACE not directly affected by ARBs [35]. Evidence indicates, however, that the beneficial effects of RAAS-modulating drugs on AF are primarily related to the angiotensin II type 1 receptor resulting in the effectiveness of both agents $[6,25]$. The present results support the hypothesis of similar effectiveness. No difference could be demonstrated in the outcome of patients on ACE-I or ARB therapy, respectively. The lesser need for reablation, i.e. $50 \%$ in the treatment group 
compared to $67 \%$ in the control group, supports the clinical effectiveness of both agents despite limited AF recurrences.

\section{Study Limitations}

The study medication was not assigned but had already been initiated at the time of study enrollment. Therefore, several agents in the ACE-I and ARB groups at variable doses were effective. The presence of asymptomatic AF episodes during long-term follow-up may have obscured some recurrences. The observation of fewer redo procedures in the treatment group is sensitive to patient discretion.

\section{Conclusion}

ACE-Is and ARBs seem to be effective for the preservation of SR after pulmonary vein isolation for paroxysmal AF. A beneficial effect of ACE-Is and ARBs after AF recurrence was possible with fewer redo procedures in patients on treatment compared to the control group.

\section{References}

1 Haissaguerre M, Jais P, Shah DC, Takahashi A, Hocini M, Quiniou G, Garrigue S, Le Mouroux A, Le Metayer P, Clementy J: Spontaneous initiation of atrial fibrillation by ectopic beats originating in the pulmonary veins. N Engl J Med 1998;339:659-666.

2 Nademanee K, McKenzie J, Kosar E, Schwab M, Sunsaneewitayakul B, Vasavakul T, Khunnawat C, Ngarmukos T: A new approach for catheter ablation of atrial fibrillation: mapping of the electrophysiologic substrate. J Am Coll Cardiol 2004;43:2044-2053.

-3 Ouyang F, Bansch D, Ernst S, Schaumann A, Hachiya H, Chen M, Chun J, Falk P, Khanedani A, Antz M, Kuck KH: Complete isolation of left atrium surrounding the pulmonary veins: new insights from the double-Lasso technique in paroxysmal atrial fibrillation. Circulation 2004;110:2090-2096.

-4 Haissaguerre M, Jais P, Shah DC, Garrigue S, Takahashi A, Lavergne T, Hocini M, Peng JT, Roudaut R, Clementy J: Electrophysiological end point for catheter ablation of atrial fibrillation initiated from multiple pulmonary venous foci. Circulation 2000;101:1409-1417.

5 Haissaguerre M, Sanders P, Hocini M, Jais P, Clementy J: Pulmonary veins in the substrate for atrial fibrillation: the 'venous wave' hypothesis. J Am Coll Cardiol 2004;43: 2290-2292.

6 Li D, Shinagawa K, Pang L, Leung TK, Car$\operatorname{din}$ S, Wang Z, Nattel S: Effects of angiotensin-converting enzyme inhibition on the development of the atrial fibrillation substrate in dogs with ventricular tachypacing-induced congestive heart failure. Circulation 2001;104:2608-2614.

7 Tsai CT, Lai LP, Lin JL, Chiang FT, Hwang JJ, Ritchie MD, Moore JH, Hsu KL, Tseng CD, Liau CS, Tseng YZ: Renin-angiotensin system gene polymorphisms and atrial fibrillation. Circulation 2004;109:1640-1646.
-8 L'Allier PL, Ducharme A, Keller PF, Yu H, Guertin MC, Tardif JC: Angiotensin-converting enzyme inhibition in hypertensive patients is associated with a reduction in the occurrence of atrial fibrillation. J Am Coll Cardiol 2004;44:159-164.

-9 Wachtell K, Lehto M, Gerdts E, Olsen MH, Hornestam B, Dahlof B, Ibsen H, Julius S, Kjeldsen SE, Lindholm LH, Nieminen MS, Devereux RB: Angiotensin II receptor blockade reduces new-onset atrial fibrillation and subsequent stroke compared to atenolol: the Losartan Intervention For End Point Reduction in Hypertension (LIFE) study. J Am Coll Cardiol 2005;45:712-719.

10 Goette A, Staack T, Rocken C, Arndt M, Geller JC, Huth C, Ansorge S, Klein HU, Lendeckel U: Increased expression of extracellular signal-regulated kinase and angiotensin-converting enzyme in human atria during atrial fibrillation. J Am Coll Cardiol 2000;35:1669-1677.

11 Madrid AH, Bueno MG, Rebollo JM, Marin I, Pena G, Bernal E, Rodriguez A, Cano L, Cano JM, Cabeza P, Moro C: Use of irbesartan to maintain sinus rhythm in patients with long-lasting persistent atrial fibrillation: a prospective and randomized study. Circulation 2002;106:331-336.

$\$ 12$ Ueng KC, Tsai TP, Yu WC, Tsai CF, Lin MC, Chan KC, Chen CY, Wu DJ, Lin CS, Chen SA: Use of enalapril to facilitate sinus rhythm maintenance after external cardioversion of long-standing persistent atrial fibrillation: results of a prospective and controlled study. Eur Heart J 2003;24:2090-2098.

13 Cappato R, Negroni S, Pecora D, Bentivegna S, Lupo PP, Carolei A, Esposito C, Furlanello F, De Ambroggi L: Prospective assessment of late conduction recurrence across radiofrequency lesions producing electrical disconnection at the pulmonary vein ostium in patients with atrial fibrillation. Circulation 2003;108:1599-1604.
14 Ouyang F, Antz M, Ernst S, Hachiya H, Mavrakis H, Deger FT, Schaumann A, Chun J, Falk P, Hennig D, Liu X, Bansch D, Kuck KH: Recovered pulmonary vein conduction as a dominant factor for recurrent atrial tachyarrhythmias after complete circular isolation of the pulmonary veins: lessons from double Lasso technique. Circulation 2005;111:127135.

15 Macle L, Jais P, Weerasooriya R, Hocini M, Shah DC, Choi KJ, Scavee C, Raybaud F, Clementy J, Haissaguerre M: Irrigated-tip catheter ablation of pulmonary veins for treatment of atrial fibrillation. J Cardiovasc Electrophysiol 2002;13:1067-1073.

16 Ventura R, Klemm H, Lutomsky B, Demir C, Rostock T, Weiss C, Meinertz T, Willems S: Pattern of isthmus conduction recovery using open cooled and solid large-tip catheters for radiofrequency ablation of typical atrial flutter. J Cardiovasc Electrophysiol 2004;15: 1126-1130.

17 Fuster V, Ryden LE, Asinger RW, Cannom DS, Crijns HJ, Frye RL, Halperin JL, Kay GN, Klein WW, Levy S, McNamara RL, Prystowsky EN, Wann LS, Wyse DG, Gibbons RJ, Antman EM, Alpert JS, Faxon DP, Fuster V, Gregoratos G, Hiratzka LF, Jacobs AK, Russell RO, Smith SC Jr, Klein WW, Alonso-Garcia A, Blomstrom-Lundqvist C, de Backer G, Flather M, Hradec J, Oto A, Parkhomenko A, Silber S, Torbicki A: ACC/AHA/ESC Guidelines for the Management of Patients With Atrial Fibrillation: Executive Summary A Report of the American College of Cardiology/ American Heart Association Task Force on Practice Guidelines and the European Society of Cardiology Committee for Practice Guidelines and Policy Conferences (Committee to Develop Guidelines for the Management of Patients With Atrial Fibrillation) Developed in Collaboration With the North American Society of Pacing and Electrophysiology. Circulation 2001;104:2118-2150. 
18 Klemm HU, Ventura R, Rostock T, Brandstrup B, Risius T, Meinertz T, Willems S: Correlation of symptoms to ECG diagnosis following atrial fibrillation ablation. J Cardiovasc Electrophysiol 2006;17:146-150.

-19 Anand K, Mooss AN, Hee TT, Mohiuddin SM: Meta-analysis: inhibition of renin-angiotensin system prevents new-onset atrial fibrillation. Am Heart J 2006;152:217-222.

20 Anne W, Willems R, Van der Merwe N, Van de Werf F, Ector H, Heidbuchel H: Atrial fibrillation after radiofrequency ablation of atrial flutter: preventive effect of angiotensin converting enzyme inhibitors, angiotensin II receptor blockers, and diuretics. Heart 2004;90:1025-1030.

-21 Coleman CI, Makanji S, Kluger J, White CM: Effect of angiotensin-converting enzyme inhibitors or angiotensin receptor blockers on the frequency of post-cardiothoracic surgery atrial fibrillation. Ann Pharmacother 2007; 41:433-437.

22 Tveit A, Grundvold I, Olufsen M, Seljeflot I, Abdelnoor M, Arnesen H, Smith P: Candesartan in the prevention of relapsing atrial fibrillation. Int J Cardiol 2006

-23 Richter B, Derntl M, Marx M, Lercher P, Gossinger HD: Therapy with angiotensinconverting enzyme inhibitors, angiotensin II receptor blockers, and statins: no effect on ablation outcome after ablation of atrial fibrillation. Am Heart J 2007;153:113-119.
24 Al Chekakie MO, Akar JG, Wang F, Al Muradi $H, W u J$, Santucci $P$, Varma $N$, Wilber DJ: The effects of statins and renin-angiotensin system blockers on atrial fibrillation recurrence following antral pulmonary vein isolation. J Cardiovasc Electrophysiol 2007; 18:942-946.

25 Kumagai K, Nakashima H, Urata H, Gondo N, Arakawa K, Saku K: Effects of angiotensin II type 1 receptor antagonist on electrical and structural remodeling in atrial fibrillation. J Am Coll Cardiol 2003;41:2197-2204.

26 Nakashima H, Kumagai K, Urata H, Gondo N, Ideishi M, Arakawa K: Angiotensin II antagonist prevents electrical remodeling in atrial fibrillation. Circulation 2000;101: 2612-2617.

27 McEwan PE, Gray GA, Sherry L, Webb DJ, Kenyon CJ: Differential effects of angiotensin II on cardiac cell proliferation and intramyocardial perivascular fibrosis in vivo. Circulation 1998;98:2765-2773.

28 Saygili E, Rana OR, Saygili E, Reuter H, Frank KF, Schwinger RH, Muller-Ehmsen J, Zobel C: Losartan prevents stretch induced electrical remodeling in cultured atrial neonatal myocytes. Am J Physiol Heart Circ Physiol 2007.

29 Oral H, Knight BP, Ozaydin M, Tada H, Chugh A, Hassan S, Scharf C, Lai SW, Greenstein R, Pelosi F Jr, Strickberger SA, Morady F: Clinical significance of early recurrences of atrial fibrillation after pulmonary vein isolation. J Am Coll Cardiol 2002;40:100104.
30 Willems S, Klemm H, Rostock T, Brandstrup B, Ventura R, Steven D, Risius T, Lutomsky B, Meinertz T: Substrate modification combined with pulmonary vein isolation improves outcome of catheter ablation in patients with persistent atrial fibrillation: a prospective randomized comparison. Eur Heart J 2006;27:2871-2878.

31 Kottkamp H, Tanner H, Kobza R, Schirdewahn P, Dorszewski A, Gerds-Li JH, Carbucicchio C, Piorkowski C, Hindricks G: Time courses and quantitative analysis of atrial fibrillation episode number and duration after circular plus linear left atrial lesions: trigger elimination or substrate modification: early or delayed cure? J Am Coll Cardiol 2004;44: 869-877.

32 Brueckmann M, Wolpert C, Bertsch T, Sueselbeck T, Liebetrau C, Kaden JJ, Huhle G, Neumaier M, Borggrefe M, Haase KK: Markers of myocardial damage, tissue healing, and inflammation after radiofrequency catheter ablation of atrial tachyarrhythmias. J Cardiovasc Electrophysiol 2004;15:686691.

33 Das UN: Is angiotensin-II an endogenous pro-inflammatory molecule? Med Sci Monit 2005;11:RA155-RA162.

34 Boos CJ, Lip GY: Prevention of atrial fibrillation by angiotensin-converting enzyme inhibitors and angiotensin II receptor blockers. J Am Coll Cardiol 2006;47:889890; author reply 890-881.

35 Ohmichi N, Iwai N, Kinoshita M: Expression of angiotensin converting enzyme and chymase in human atria. J Hypertens 1997; 15: 935-943. 